\section{ALGILANAN ÖRGÜTSEL DESTEĞİN ÇALIȘANLARIN İÇ GIRIŞIMCIILIK PERFORMANSLARI ÜZERINDEKI ETKISINININ İNCELENMESI}

Bu çalışma, 24. Ulusal Yönetim ve Organizasyon Kongresi'nde (İstanbul) sunulan bildirinin genişletilmiș tam metin halidir.

\author{
Makale Gönderim Tarihi: 22.06.2016 \\ Engin KANBUR \\ Yrd.Doç.Dr., \\ Kastamonu Üniversitesi \\ Sivil Havacilık \\ Yüksekokulu \\ ekanbur@kastamonu.edu.tr
}

Yayına Kabul Tarihi: 21.09.2016

\section{ÖZI}

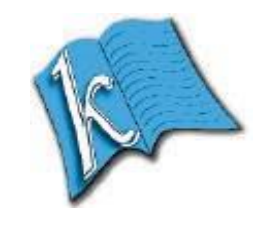

Kafkas Üniversitesi İktisadi ve İdari Bilimler Fakültesi Dergisi KAÜİIBBD,

Cilt. 7, Say1. 14, 2016 ISSN: $1309-4289$ E - ISSN: 2149-9136
Rekabet edebilmenin ve bunu sürdürülebilir kılmanın zorlaştığı günümüz iş dünyasında örgütler çalışanlarının daha yenilikçi, özgün, risk alabilen ve proaktif davranışlar sergileyebilen bireyler olabilmesi için onları her konu ve her alanda desteklemelidir. Her geçen gün birbirine benzeyen, taklit edilebilen yönetim anlayışları, teknolojileri, ürün yelpazeleri ve sürekli değişen tüketici davranışları karşısında örgütler de kendilerini değiştirmeli ve geliştirmelidir. Örgütler bu değişim ve gelişim sürecinin başarılı olabilmesinin en önemli kaynağı olan çalışanlarına destek vererek onların iç girişimcilik performanslarını harekete geçirebilir ve sürekliliğini sağlayabilirler. $\mathrm{Bu}$ çalışmanın amacı, algılanan örgütsel desteğin çalışanların iç girişimcilik performansları üzerindeki etkisinin incelenmesidir. Araştırma 2014 yılında Silverline A.Ş.'deki 384 çalışan ile anket yöntemi kullanılarak gerçekleştirilmiştir. Araştırmanın yapı geçerliliğini test etmek amacıyla açıklayıcı faktör analizi, değişkenler arasındaki ilişkinin şiddetini ve yönünü ölçmek için korelasyon analizi, değişkenler arasındaki nedenselliği ölçmek için ise regresyon analizi kullanılmıştır. Araştırmanın sonucunda, algılanan örgütsel desteğin çalışanların iç girişimcilik ve alt boyutlarından "yenilik, risk alma, proaktiflik ve özerklik" performansları üzerindeki etkisi olduğu, fakat "risk alma" performansı üzerinde ise etkili olmadığı tespit edilmiştir.

Anahtar Kelimeler: Algllanan örgütsel destek, iç girişimcilik, yenilik.

JEL kodlart: M12, M19

Türü: Araştırma

DOI:10.9775/kauiibfd.2016.021

Atıfta bulunmak için: KANBUR, E. (2016) "Algılanan Örgütsel Desteğin Çalışanların İç Girişimcilik Performansları Üzerindeki Etkisinin İncelenmesi” KAÜIIIBFD 7(14), 443-460. 


\title{
EXAMINING THE EFFECTS OF PERCEIVED ORGANIZATIONAL SUPPORT ON INTRAPRENEURSHIP PERFORMANCE OF EMPLOYEES
}

\author{
Kafkas University \\ Journal of Economics and \\ Administrative Sciences Faculty \\ KAUJEASF \\ Vol. 7, No. 14, 2016 \\ ISSN: $1309-4289$ \\ ISSN: $1309-4289$
E- ISSN: $2149-9136$
}

\section{Article Submission Date: 22.06.2016 Accepted Date:21.09.2016}

ABSTRACT In today's business world, in

Engin KANBUR

Assistant Professor

Kastamonu

University

School of Civil

Aviation

ekanbur@kastamonu. edu.tr which being competitive and making this sustainable becomes more difficult, organizations should support their employees in every field to make them individuals who demonstrate more innovative, unique, risk-taking and proactive behaviors. Under the circumstances of more imitable and more similar management approaches, technology, product range and continuously changing consumer behaviors organizations have to change and develop themselves. For being successful in this change and development process, organizations can motivate their employees' intrapreneurship performance and keep organizatinal sustainability by providing support to them regarding organizations most important resource. The purpose of this study is to examine the effects of perceived organizational support on intrapreneurship performance of employees. The research was conducted using the survey method with 384 employees at the Silverline Inc. in the 2014. The exploratory factor analyze to test the structural validity of the study the Pearson correlation analyze to measure the intensity and direction of relationships between variables and the simple linear regression analyze the causality between variables was utilized in the study. As a result of the study it is found that perceived organizational support have pozitive effects on intrapreneurship performance of employees and "innovation, proactivity and autonomy" as its dimensions, but also, perceived organizational support has no effects on "risk taking" as a dimension of intrapreneurship performance of employees.

Keywords: Perceived organizational support, intrapreneurship, innovation

JEL Codes: M12, M19

Type: Research

Cite this Paper: KANBUR, E. (2016) "Examining the Effects of Perceived Organizational Support on Intrapreneurship Performance of Employees" KAUJEASF 7(14), 443-460. 


\section{GÍRİS}

Küreselleşme olgusunun doğal sonucu olarak değișen ve gelișen teknolojik koşullar, acımasızlaşan rekabet ortamı, ekonomik belirsizlikler sonucunda oluşan kaotik ve karmaşık ortam örgütlerin hayatta kalabilmesi ve varlıklarını sürdürebilmesi için en değerli kaynağı olan çalışanlarını örgüte bağlamalı, tatmin etmeli, yaratıcı düşenlerini ön plana çıkararak yenilik faaliyetlerinde bulunmalarını sağlamalı, risk alabilen, proaktif (öngörümcü) ve özgün bireyler olmalarını sağlayabilmelidirler. Örgütler, çalışanlarının iç girişimcilik performanslarını harekete geçirmek ve sürekli kılmak için onların beklentilerine cevap verebilmeli, yaratıcılık ve iç girişimcilik performanslarını ortaya koyabilecek ortamlar sağlanmalı ve her konuda destek verilmelidirler. $\mathrm{Bu}$ anlamda örgütsel destek, çalışanın örgüt içinde amaçlarını gerçekleştirebilmesi için verdiği katkı ve gösterdiği çaba sonucunda, örgütün de çalışana verdiği destek, maddi ve manevi ödül olarak tanımlamak mümkündür (Eisenberger vd., 2004: 565). Çalışanların örgüt tarafından verilen bu desteğin iyi farkında olmaları ya da iyi algılamaları onların iç girişimcilik performansları üzerinde etkili olacaktır. Bu bağlamda, algılanan örgütsel destek, örgütün çalışanın çabasına, emeğine değer vermesi ve refahını önemsemesine yönelik algılar ile çalışanları etkileyen tüm faaliyetlerin örgüt tarafından gönüllü olarak gerçekleştirdiğine ilişkin algılar olarak belirtilebilir.

$\mathrm{Bu}$ yönüyle hızla değişen dinamik örgüt çevresinde belirsizlikler artmakta, yeni firsat ve tehditler çoğalmakta, karmaşıklık ve kaotik ortamlar oluşmaktadır.

Örgütler, bu belirsizlik ve kaotik ortamlarda tehditlere karşı önceden hazırlıklı olmalı ve bunları fırsatlara çevirip yeniliğe dönüștürerek rakiplerine karş1 rekabet avantajı sağlamalıdırlar. Örgüt içerisinde bu tür girişimcilik faaliyetlerini gerçekleştirmek "iç girişimcilik" kavramını ortaya çıkarmaktadır. İç girişimcilik, mevcut girişimcilik kaynaklarının ve çalışanların yaratıcılıklarının kullanılarak örgüt içinde yeni faaliyetlerin oluşturulması sürecidir (Chang, 2001:154). İç girişimcilik, örgütlerin dinamik ve belirsizliklerle dolu iş çevresinde rekabet avantajı elde etmelerinde bilgi, beceri ve yeteneklerini güçlendirirken, yetkinliklerini arttırmaktadır (Felicio vd., 2012:1720).

Örgütler, içinde bulundukları sektörün tehditlerini öngörüp firsata çeviren, belirsizlik anında risk alabilen, özgün ve yaratıcı fikirlere sahip olan ve bunları yeniliğe dönüştürebilen, takım sinerjisine uyum sağlayabilen çalışanlara ihtiyaç duyarlar. Örgütler böyle bir çalışan grubu oluşturabilmek için onlara her konuda destek vermelidirler. Bu çalışma son zamanlarda örgütler için önemli olan iç girişimcilik faaliyetlerinin gerekliliğini ortaya koymak ve yazındaki eksikliği giderebilmek amacıyla hazırlanmıştır. 


\section{KAVRAMSAL CERÇEVE}

\subsection{Algılanan Örgütsel Destek}

Eğitim seviyesi yüksek, teknolojiyi iyi kullanabilen, örgütler ve sektörler arasında kıyaslama yapabilen, yetenek ve tecrübelerini diğer çalışanlarla karşılaştırabilen çalışanların örgütten beklentilerinin arttı̆̆ günümüzde (Turunç ve Çelik, 2010: 184), örgütleri destekleyecek çalışan tutumları ve algılarının oluşturulmasının, örgütlerin önünde zorlu bir mücadele alanı olarak durduğunu söylemek mümkündür (Tozgöz, 2011: 364). Örgütsel destek, bir örgütün, çalışanın örgüte katkılarının bilincinde olması ve çalışanın refahına önem vermesidir (Akın, 2008: 142; Zacher ve Winter, 2011: 665). Örgütsel destek, çalışanın örgüt içinde amaçlarını gerçekleştirebilmesi için verdiği katkı sonucunda, örgütün de çalışana verdiği destek, maddi ve manevi ödül olarak tanımlanabilir (Eisenberger vd., 2004: 565). Ayrıca, örgütsel destek, bireyin örgüt tarafindan kendisine ne kadar destek verildiğini hissetmesi ve düşünmesi, örgütteki çalışanların kendisine değer verildiği ve mutluluğunun önemsendiğine yönelik bir algılama tarzıdır (Yıldız vd., 2015: 1409; Kasalak ve Aksu, 2014: 117; Bashir, 2012: 66; Cao vd., 2014: 2014; Eisenberger vd., 1986: 501; Bogler ve Nir, 2012: 288; Byrne ve Hochwarter, 2008: 54; Y1ld1z ve Y1ld1z, 2015: 70-71)

Algllanan örgütsel destek (AÖD), sosyal mübadele kuramı ve karş1lıklı ilişkiler normundan doğmakta (DeConinck ve Johnson, 2009: 335; Moon vd., 2013: 109; Suazo ve Turnley, 2010: 628; Y1ld1z ve Y1ld1z, 2016: 20) ve en temel anlamıyla örgüt ile çalışanlar arasındaki sosyal bir değişim ilişkisini ifade etmektedir (Allen ve Shanock, 2013: 353; Yıldız ve Yıldız, 2016: 20). AÖD, örgütün çalışanın katılımına önem vermesi ve refahını önemsemesine yönelik algılar ve çalışanları etkileyen faaliyetleri örgütün gönüllü olarak gerçekleştirdiğine ilişkin duygular olarak tanımlanmakta (Akkoç vd., 2012: 113; Hellman vd., 2006: 631) ve örgüte karş1 yükümlülük duygusunu geliştirme eğilimindedir (Hashemi vd., 2012: 84). Çalışanların örgütün faydasına yönelik davranışları göstermeleri ise ancak örgütün çalışanlara verdiği değer ve sağladığ 1 destek, çalışanların örgütten duydukları tatmin ve örgüte olan bağl1lıkları sonucunda gerçekleşebilmektedir (Duygulu vd., 2008: 109; Gavino vd., 2012: 666). AÖD, örgütsel amaçlara ulaşmada, iş doyumu sağlamada ve örgütsel performansı yükseltmede oldukça önemli bir yere sahiptir (Boyer vd., 2014: 87; Eder ve Eisenberger, 2008: 55; Neves ve Eisenberger, 2012: 455; Potts ve Reynolds, 2010: 94).

\section{2. İç Girişimcilik}

Küreselleşme ile tek pazar haline gelen dünyada, örgütlerin ayakta kalabilmeleri ve rekabet üstünlüğünü sağlayabilmeleri ihtiyac1 "iç girişimcilik" kavramını ortaya çıkarmıştır (Basım vd., 2009: 4). İç girişimcilik kavramı, 
1980'lerin ortasında ayrı bir araştırma konusu olarak yazındaki yerini almıştır. Günümüzde hala açık ve ortak bir tanımı bulunmayan ama her geçen gün önemi daha da artan bir kavram haline gelmiştir (Christensen, 2005: 307; Ebner vd., 2007: 291). Araştırmacılar iç girişimciliğin farklı yönlerini ortaya koymak için farklı kavramlar kullanmışlardır. Bunlar, intrapreneurship (iç girişimcilik), corporate entrepreneurship (kurumsal girişimcilik), internal corporate entrepreneurship (iç kurumsal girişimcilik), exopreneurship (yenilik için seçenek), corporate ventures (kurumsal girişimler), new ventures (yeni girişimler) gibi kavramlardır (Borza ve Maier, 2012: 15; Chang, 2001: 154; Molina ve Callahan, 2009: 389; Demirel ve Özbezek, 2015: 117). İç girişimcilik, bir örgüt içerisinde, örgütsel karlılığı ve örgütün rekabet gücünü yükseltmek ve stratejik yenilenmeyi gerçekleştirebilmek için yeni iş yaratma sürecidir (Zahra, 1991, Akt. Gürel, 2012: 59). İç girişimcilik, stratejik yenilenmeyi, rekabet pozisyonunu, örgütsel karlılığ imkanları ve yeni fikirleri geliştirmeyi amaçlamaktadır (Ramanigopal vd., 2012: 51; Wyk ve Adonisi, 2002: 66; Scott vd., 2013: 331). İç girişimcilik, örgütlerin rekabet avantaji elde etmelerinde beceri ve yeteneklerini güçlendirirken, yetkinliklerini artırır (Felicio vd., 2012: 1720).

İç girişimciliğin dört boyutu vardır. Bunlar, yenilik, risk alma, proaktiflik ve özerkliktir (Bouchard ve Basso, 2011: 221; Soleimani vd., 2013: 1644; Moriano vd., 2014: 103). Yenilik, değer yaratmak için eskiyi geliştirerek yeni ürünlerin, üretim süreçlerinin, hizmet ve organizasyonların araştırılması, bulunması, planlanması, denenmesi, geliştirilmesi, izlenmesi ve benimsenmesidir (Koç ve Mente, 2007: 1; Warrian ve Mulhern, 2005: 163; Moura ve Abrunhosa, 2007: 58; Kanbur ve Kanbur, 2014: 11). Yenilik, yaratıc1 düşünce ile başlayan önemli bir süreçtir (Kanbur, 2015: 40). Risk alma, örgütün sonucunu bilmeden yabancı pazarlara girişi (Stull ve Aram, 2010: 19) veya yenilikçi projeleri desteklemeye yönelik örgütün eğilimidir (Zahra ve Garvis, 2000: 471). Proaktiflik, hızla değişen çevresel koşullara uyabilmek ve bir adım öne geçebilmek amaciyla çevrenin gelecekteki taleplerini öngörerek olası taleplere rakiplerden daha önce cevap verebilecek yapıda lider olabilmektir (İçerli vd., 2011: 180). Özerklik bir iş fikrini ortaya çıkarmak, geliştirmek ve sonuna kadar götürmek konusunda birey ya da ekip tarafindan yürütülen bağımsız davranışlar olarak tanımlanabilir (Fiş ve Wasti, 2009: 132).

\subsection{Algılanan Örgütsel Destek ile İç Girişimcilik Arasındaki İlişki}

Hızlı teknolojik değişimler, yaşanan ekonomik krizler, uluslararası artan rekabet, değişen ve taklit edilen çekirdek yetenekler karşısında örgütlerin yeni değerler yaratması ve geliştirmesi iç girişimcilik kavramını ortaya çıkarmıştır (Rigtering ve Weitzel, 2013: 338). Küreselleşme ile tek pazar haline gelen dünyada, örgütlerin ayakta kalabilmeleri ve rekabet üstünlügünü 
sağlayabilmeleri açısından iç girişimcilik büyük önem taşımaktadır (Basım vd., 2009: 4). Örgütlerin, çalıșanları ve onların yetenekleri olmadan bu amaçlara ulaşabilmesi oldukça güçtür. Çalışanlar ve örgütleri arasındaki sosyal değişim süreci (Hu vd., 2014: 24) olarak adlandırılan algılanan örgütsel destek kavramı çalışanların iç girişimcilik performanslarını harekete geçirmek ve sürekli kılmak adına anlamlıdır.

Hipotez 1: Algılanan örgütsel destek çalışanların iç girişimcilik performanslarını pozitif yönde etkiler.

Örgütler, çalışanlarının yaratıcı düşünce ve fikirlerini örgüt amaçları doğrultusunda harekete geçirebilmesi, yenilik yapabilmesi, gerektiğinde ve yeterince risk alabilmesi, özgün olabilmesi ve gelecekte olması muhtemel firsat ve tehditleri öngörebilmesi (proaktiflik) için onlara destek olmalıdır.

Hipotez 1a: Algılanan örgütsel destek çalışanların iç girişimcilik boyutlarından "yenilik" performansını pozitif yönde etkiler.

Hipotez 1b: Algılanan örgütsel destek çalışanların iç girişimcilik boyutlarından "risk alma" performansını pozitif yönde etkiler.

Hipotez 1c: Algılanan örgütsel destek çalışanların iç girişimcilik boyutlarından "proaktiflik" performansını pozitif yönde etkiler.

Hipotez 1d: Algılanan örgütsel destek çalışanların iç girişimcilik boyutlarından "özerklik" performansını pozitif yönde etkiler.

Çalışmanın temel amacı, sorunsalı ve hipotezleri ışığında oluşturulan araştırma modeli Şekil 1'de sunulmuştur.

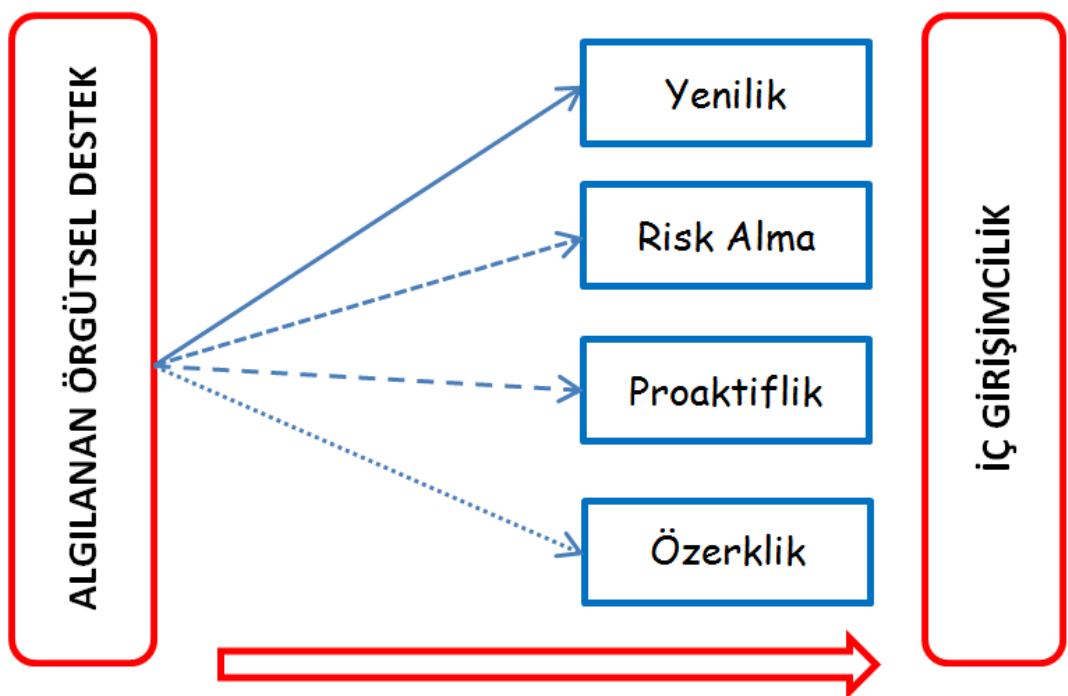

Şekil 1. Araştırma Modeli 


\section{ARAŞTIRMANIN METODOLOJISİ}

\subsection{Araştırmanın Amacı ve Önemi}

Sosyal mübadele kuramı, örgütsel destek kuramı, karşılıklılık normu gibi kuramlar "kazan-kazan" mantığ 1 ile örgütün çalıșana verdikleri veya sağladıkları imkanlar karşısında çalışanın da buna karşı1ık vermekte olduğunu ve her iki tarafin da kazançlı çıktığını vurgulamaktadır. Çalışanların çift taraflı fayda temelinde geliştirdikleri değişim ilişkisinin çalışanların hem rol içi hem de rol dışı performanslarında etkili olabileceği söylenebilir (Tüzün ve Kalemci, 2016: 560). Bu kapsamda araştırmanın temel amacı, algılanan örgütsel desteğin çalışanların iç girişimcilik performansları üzerinde etkisinin ne düzeyde olduğunun ortaya konulmasıdır.

\subsection{Araștırmanın Evreni ve Örneklemi}

Araştırmanın evreni ve örneklemi, Türkiye'nin en büyük davlumbaz ve aspiratör üreticisi, Avrupa'da ilk 10 davlumbaz üreticisi içinde yer alan, iç pazarda ankastre sektöründe üçüncü sırada olan ve 2014 yılının en yenilikçi ankastre markası seçilen Silverline A.Ş.'deki 842 çalışandır. Basit tesadüfi örnekleme yöntemi ile belirlenen çalışanlara 400 adet anket formu dağıtılmış ve \%98 yanıtlanma oranıyla 392 anketin geri dönüşümü sağlanmıştır. 392 yanıtlanan anketin 6'si tamamlanmamış ve 2'si güvenilmeyen yanıtlar yüzünden araştırmaya dahil edilmemiştir. Böylece araştırmaya son olarak veri analizleri için 384 kullanılabilir anket dahil edilmiştir. Veri toplama süreci tamamlandığında araştırmada yer alan 384 katılımcı, araştırma evrenini \%99 $(\alpha=.01)$ güven düzeyi ve \pm .01 hata seviyesinde temsil edecek niteliktedir.

\subsection{Araştırmada Kullanılan Ölçekler}

\subsubsection{Algılanan Örgütsel Destek Ölçeği}

Araştırmada çalışanların örgütsel destek algılamalarını ölçmek amacıyla “Algılanan Örgütsel Destek Ölçeği” kullanılmıştır. Eisenberger ve arkadaşları (1986) tarafindan 36 soruluk uzun formu geliştirilen ölçeğin yine Eisenberger ve arkadaşları (1997) ile Lynch ve arkadaşları (1999) tarafindan kısaltılmış hali kullanılmıştır. Eisenberger ve arkadaşları (1997)'nın çalışmalarında kullandıkları ölçeğin Türkçe geçerlemesi ölçek uyarlama prosedürlerine uygun olarak tarafımızdan yapılmıştır. Ölçeğin İngilizce-Türkçe çevirileri alanyazını bilen ve bilmeyen uzman kişiler tarafindan yapılmıştır. Yapılan çeviriler kısa, anlaş11ır, kültüre uygun olacak şekilde birleştirildikten sonra Türkçe alanında uzman kişiler tarafından değerlendirilerek ölçek hazır hale getirilmiştir. Ölçek tek boyuttan ve 8 sorudan oluşmaktadır. Bu bölümdeki sorular "Çalıştığım işletme, fikirlerime önem verir.", Çalıştığım işletme, bir problemim olduğu zaman yardım etmeye hazırdır." şeklindedir. Ölçekte ters puanlı 2 soru bulunmaktadır. Puanlama, 5'li likert ölçeğine göre yapılmıştır $(1=$ kesinlikle katılmiyorum; 5=kesinlikle katılıyorum). 


\subsection{2. İç Girişimcilik Ölçeği}

Çalışanların iç girișimcilik performanslarının belirlenmesi amacıyla, Naktiyok (2004) tarafindan geliştirilen ve Durmaz (2011) tarafindan doktora tezinde kullanılan, geçerliliği ve güvenilirliliği test edilmiş "Iç Girişimcilik Ölçeğị" kullanılmıştır. Ölçek, Yenilik, Risk alma, Proaktiflik ve Özerklik olmak üzere dört boyuttan ve 21 sorudan oluşmaktadır. Bu bölümdeki sorular "Yeni fikirlere açık biri olduğumu düşünüyorum", "Görevin başarısına inanırsam her türlü riski üstlenebilirim" ve "Yeni bir proje üzerinde çalışırken gideceğim yön konusunda her türlü özgürlüğe sahibim" şeklindedir. Beşli likert ölçeği kullanılmıştır ( $1=$ kesinlikle katılmıyorum; $5=$ kesinlikle katılıyorum).

\subsection{Faktör Analizi ve Güvenilirlik Analizi}

Araştırmada kullanılan ölçeklerin yapı geçerliliğini ölçmek amacıyla faktör analizinden yararlanılmış olup, sonuçlar Tablo 1'de gösterilmektedir.

Tablo 1. Faktör Analizi ve Bulguları

\begin{tabular}{lccc}
\hline \multicolumn{4}{c}{ Algılanan Örgütsel Destek Ölçeği } \\
\hline \multicolumn{1}{c}{ Faktörler } & $\begin{array}{c}\text { İfade } \\
\text { Sayısı }\end{array}$ & $\begin{array}{c}\text { Faktör Yükleri } \\
\text { Aralığı }\end{array}$ & $\begin{array}{c}\text { Açıklanan Varyans } \\
(\%)\end{array}$ \\
\hline $\begin{array}{l}\text { Algılanan Örgütsel } \\
\text { Destek }\end{array}$ & 8 &, $545-, 882$ & 59,361 \\
\hline
\end{tabular}

Kaiser-Meyer-Olkin örneklem yeterliliği değeri: ,908

Barlett küresellik testi: ki-kare $=1807,649 ; \mathrm{sd}=28 ; \mathrm{p}=, 000$

Açılanan Toplam Varyans: \% 59,361

\begin{tabular}{lccc}
\hline \multicolumn{4}{c}{ İç Girişimcilik Ölçeği } \\
\hline \multicolumn{1}{c}{ Faktörler } & $\begin{array}{c}\text { İfade } \\
\text { Sayısı }\end{array}$ & $\begin{array}{c}\text { Faktör Yükleri } \\
\text { Aralığı }\end{array}$ & $\begin{array}{c}\text { Açılanan Varyans } \\
(\%)\end{array}$ \\
\hline İç Girişimcilik & 21 &, $531-, 888$ & 62,768 \\
\hline Yenilik & 5 &, $664-, 784$ & 18,126 \\
\hline Risk Alma & 4 &, $600-, 888$ & 17,815 \\
\hline Proaktiflik & 6 &, $540-, 819$ & 14,795 \\
\hline Özerklik & 6 &, $531-, 874$ & 12,033 \\
\hline
\end{tabular}

Kaiser-Meyer-Olkin örneklem yeterliliği değeri: ,806

Barlett küresellik testi: ki-kare $=5803,433 ; \mathrm{sd}=210 ; \mathrm{p}=, 000$

Açılanan Toplam Varyans: \%62,768 
Araştırmada, algılanan örgütsel destek ölçeği, iç girişimcilik ölçeği ve boyutları iç tutarlılık analizi Cronbach Alfa ile incelenmiş olup, sonuçlar Tablo 2'de gösterilmektedir.

Tablo 2. Ölçeklere İlişkin Güvenilirlik Değerleri

\begin{tabular}{lc}
\hline Ölçek & Cronbach Alpha $(\boldsymbol{\alpha})$ \\
\hline Algılanan Örgütsel Destek & $.89,8$ \\
İç Girişisimcilik & $.84,6$ \\
• Yenilik & $.83,3$ \\
• Risk Alma & $.78,3$ \\
• Proaktiflik & $.87,1$ \\
• Özerklik & $.87,0$ \\
\hline
\end{tabular}

4. ARAŞTIRMANIN BULGULARI

4.1. Katılımcıların Demografik Özelliklerine İlişkin Bulgular

Araştırmaya katılanların demografik özelliklerine ilişkin bulgular Tablo 3'de görülmektedir.

Tablo 3. Katılımcıların Demografik Özelliklerine İlişkin Bulgular

\begin{tabular}{|c|c|c|c|c|c|}
\hline $\begin{array}{l}\text { Demografik } \\
\text { Özellik }\end{array}$ & $\mathbf{n}$ & $\%$ & $\begin{array}{l}\text { Demografik } \\
\text { Özellik }\end{array}$ & $\mathbf{n}$ & $\%$ \\
\hline Cinsiyet: & & & Medeni Durum: & & \\
\hline Kadın & 36 & 9,4 & Evli & 181 & 47,1 \\
\hline Erkek & \multirow[t]{2}{*}{348} & \multirow[t]{2}{*}{90,6} & Bekar & \multirow[t]{2}{*}{203} & \multirow[t]{2}{*}{52,9} \\
\hline Eğitim Durumu: & & & Yaş: & & \\
\hline İlköğretim & 29 & 7,6 & $16-22$ aras 1 & 35 & 9,1 \\
\hline Lise & 229 & 59,6 & $23-29$ aras1 & 144 & 37,5 \\
\hline Önlisans & 59 & 15,4 & $30-36$ aras1 & 159 & 41,4 \\
\hline Lisans & 56 & 14,6 & $37-43$ aras 1 & 35 & 9,1 \\
\hline Lisansüstü & \multirow[t]{2}{*}{11} & \multirow[t]{2}{*}{2,9} & 44 yaş ve üzeri & \multirow[t]{2}{*}{11} & \multirow[t]{2}{*}{2,9} \\
\hline $\begin{array}{l}\text { İşyerinizdeki } \\
\text { Kıdem: }\end{array}$ & & & Toplam Kıdem: & & \\
\hline 3 y1l ve altı & 125 & 32,6 & 3 y1l ve altı & 78 & 20,3 \\
\hline 4-7 yıl arası & 138 & 35,9 & 4-7 yıl arası & 101 & 26,3 \\
\hline
\end{tabular}




\begin{tabular}{|c|c|c|c|c|c|}
\hline 8-11 yıl aras1 & 72 & 18,8 & $8-11$ y1l arası & 123 & 32,0 \\
\hline $12-15$ yıl aras1 & 38 & 9,9 & $12-15$ yıl arası & 59 & 15,4 \\
\hline 16 yıl ve üzeri & 11 & 2,8 & 16 yıl ve üzeri & 23 & 6,0 \\
\hline Toplam & 384 & 100 & Toplam & 384 & 100 \\
\hline \multicolumn{6}{|c|}{ 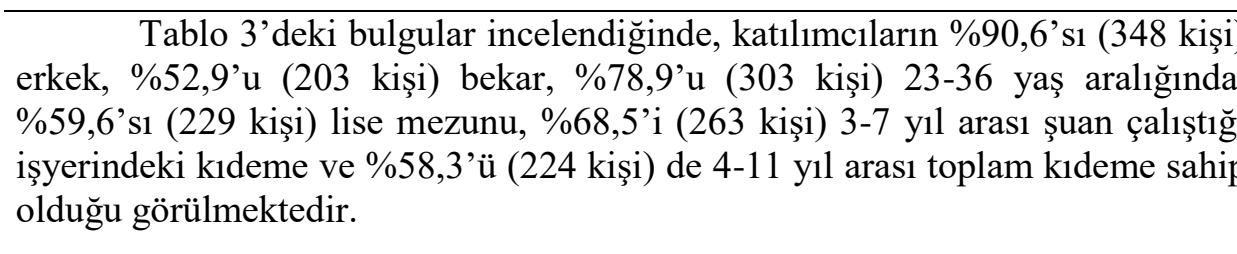 } \\
\hline
\end{tabular}

\subsection{Korelasyon Analizi ve Bulguları}

Araştırmada algılanan örgütsel destek ve iç girişimcilik değişkenleri arasındaki ilişkiyi tespit etmek amacıyla korelasyon analizi, bağımsız değişkenlerin bağımlı değişken üzerindeki etkisini tespit etmek amacıyla da regresyon analizi kullanılmıştır (Tablo 4, 5 ve 6).

Tablo 4. Değişkenler Arasındaki Korelasyon Analizi ve Bulguları

\begin{tabular}{|c|c|c|c|c|c|c|c|c|c|}
\hline & Değişkenler & Ort. & Std.S & 1 & 2 & 3 & 4 & 5 & 6 \\
\hline & ALGILANAN & & & & & & & & \\
\hline 1 & $\begin{array}{l}\text { ÖRGÜTSEL } \\
\text { DESTEK }\end{array}$ & 3,41 & 883 & 1 & & & & & \\
\hline 2 & $\begin{array}{l}\text { İÇ } \\
\text { GİRİ̧̧IMCILIIK }\end{array}$ & 3,49 &, 517 &, $384^{*}$ & 1 & & & & \\
\hline 3 & Yenilik & 3,81 &, 804 &, $389^{*}$ &, $676^{*}$ & 1 & & & \\
\hline 4 & Risk Alma & 3,63 &, 722 &,- 054 &, $287^{*}$ &,- 021 & 1 & & \\
\hline 5 & Proaktiflik & 3,67 &, 769 &, $388^{*}$ &, $794^{*}$ & ,618 &, 017 & 1 & \\
\hline 6 & Özerklik & 2,95 & ,913 &, $176^{*}$ &, $665^{*}$ &, $096^{* *}$ &, 041 &, $267^{*}$ & 1 \\
\hline
\end{tabular}

Tablo 4'deki bulgular incelendiğinde; algılanan örgütsel destek ile iç girişimcilik $(\mathrm{r}=, 384 ; \mathrm{p}=, 000)$ ve alt boyutları olan, yenilik $(\mathrm{r}=, 389 ; \mathrm{p}=, 000)$, proaktiflik $(\mathrm{r}=388 ; \mathrm{p}=, 000)$ ile özerklik $(\mathrm{r}=, 176 ; \mathrm{p}=, 003)$ boyutları arasında pozitif yönde ve anlamlı korelasyonlar olduğu görülürken, algılanan örgütsel destek ölçeğindeki en yüksek korelasyon ise iç girişimcilik ölçeği ile aynı ölçeğin yenilik ve proaktiflik boyutlarında gerçekleşirken, risk alma boyutunda $(\mathrm{r}=,-, 054 ; \mathrm{p}=, 295)$ ise istatistiksel açıdan anlamlı bir ilişkiye rastlanmamıştır. 


\subsection{Regresyon Analizi ve Bulguları}

Bağımsız değişkenlerin bağımlı değişken ve alt boyutları üzerindeki etkisini tespit etmek amaciyla ise basit doğrusal regresyon analizleri kullanılmıştır (Tablo 5 ve 6).

Tablo 5. Algılanan Örgütsel Desteğin İç Girişimcilik Üzerindeki Etkisini İncelemeye Yönelik Regresyon Analizi ve Bulguları

\begin{tabular}{|l|c|c|c|c|c|c|}
\hline Bağımlı Değişken: İç Girişimcilik \\
\hline Bağımsız değişken & $\mathbf{R}^{\mathbf{2}}$ & $\mathbf{F}$ & $\boldsymbol{\beta}$ & $\mathbf{t}$ & $\mathbf{p}$ & $\begin{array}{c}\text { Durbin- } \\
\text { Watson }\end{array}$ \\
\hline $\begin{array}{l}\text { Algılanan Örgütsel } \\
\text { Destek }\end{array}$ &, 147 & $66,074^{*}$ &, 384 & 8,129 &, $000^{*}$ & 1,676 \\
\hline
\end{tabular}

$* \mathrm{p}<0.01$ düzeyinde anlamlıdır.

Tablo 5'de yer alan regresyon analizine ilişkin bulgular incelendiğinde, iç girişimcilik değişkeninin \%14.7'sinin algılanan örgütsel destek değişkeni tarafindan açıklandığı $\left(\mathrm{R}_{2}=, 147\right)$ ve $66,074 \mathrm{~F}$ değeri ile \%99 güven aralığında diğer bir ifadeyle $p<0,01$ düzeyinde anlamlı olduğu görülmektedir. DurbinWatson istatistiği değeri 1,676 olup, otokorelasyon olmadığı söylenebilir. Tüm bu bulgular 1şı̆̆ında, algılanan örgütsel destek faaliyetlerinin çalışanların iç girişimcilik performanslarını anlamlı ve pozitif yönde etkilediği $\left(\mathrm{H}_{1}\right)$ hipotezi desteklenmiş $(\beta=, 384, p=, 000)$ olup, iç girişimciliğin alt boyutlarına ilişkin analizler ve bulguları Tablo 6 ' da gösterilmektedir.

Tablo 6. Algılanan Örgütsel Desteğin İç Girişimciliğin Alt Boyutları Üzerindeki Etkisini İncelemeye Yönelik Regresyon Analizi ve Bulguları

\begin{tabular}{|c|c|c|c|c|c|c|}
\hline \multicolumn{7}{|c|}{ Bağımlı Değişken: Yenilik } \\
\hline Bağımsız değişken & $\mathbf{R}^{2}$ & $\mathbf{F}$ & $\boldsymbol{\beta}$ & $\mathbf{t}$ & $\mathbf{p}$ & $\begin{array}{l}\text { Durbin- } \\
\text { Watson }\end{array}$ \\
\hline $\begin{array}{l}\text { Algulanan Örgütsel } \\
\text { Destek }\end{array}$ &, 151 & $68,165^{*}$ &, 389 & 8,256 &, $000 *$ & 1,917 \\
\hline \multicolumn{7}{|c|}{ Bağımlı Değişken: Risk Alma } \\
\hline Bağımsız değişken & $\mathbf{R}^{2}$ & $\mathbf{F}$ & $\boldsymbol{\beta}$ & $\mathbf{t}$ & $\mathbf{p}$ & $\begin{array}{l}\text { Durbin- } \\
\text { Watson } \\
\end{array}$ \\
\hline $\begin{array}{l}\text { Algılanan Örgütsel } \\
\text { Destek }\end{array}$ &, 003 & 1,099 &,- 054 & 1,048 & ,295 & 1,619 \\
\hline \multicolumn{7}{|c|}{ Bağımlı Değişken: Proaktiflik } \\
\hline Bağımsız değişken & $\mathbf{R}^{2}$ & $\mathbf{F}$ & $\boldsymbol{\beta}$ & $\mathbf{t}$ & $\mathbf{p}$ & $\begin{array}{l}\text { Durbin- } \\
\text { Watson }\end{array}$ \\
\hline $\begin{array}{l}\text { Algılanan Örgütsel } \\
\text { Destek }\end{array}$ &, 151 & $67,848 *$ & ,388 & 8,237 &, $000 *$ & 1,793 \\
\hline
\end{tabular}




\begin{tabular}{|l|c|c|c|c|c|c|}
\hline Bağımlı Değişken: Ö̈erklik \\
\hline Bağımsız değişken & $\mathbf{R}^{\mathbf{2}}$ & $\mathbf{F}$ & $\boldsymbol{\beta}$ & $\mathbf{t}$ & $\mathbf{p}$ & $\begin{array}{c}\text { Durbin- } \\
\text { Watson }\end{array}$ \\
\hline $\begin{array}{l}\text { Algılanan Örgütsel } \\
\text { Destek }\end{array}$ &, 031 & $12,247^{*}$ &, 176 & 3,500 &, $001 *$ & 1,683 \\
\hline
\end{tabular}

${ }^{*} \mathrm{p}<0.01$ düzeyinde anlamlıdır.

Tablo 6'da yer alan, algılanan örgütsel destek ile iç girişimcilik alt boyutları arasındaki regresyon analizine ilişkin bulgular incelendiğinde, yenilik boyutunun \%15.1'inin $\left(\mathrm{R}_{2}=151 ; \mathrm{F}=68,165 ; \mathrm{p}=, 000\right)$, proaktiflik boyutunun \%151'inin $\left(\mathrm{R}_{2}=, 151 ; \mathrm{F}=67,848 ; \mathrm{p}=, 000\right)$ ve özerklik boyutunun \%3.1'inin $\left(\mathrm{R}_{2}=, 031 ; \mathrm{F}=12,247 ; \mathrm{p}=, 001\right)$, algılanan örgütsel destek değişkeni tarafindan açıklandığı ve regresyon modellerinin \%99 güven aralığında diğer bir ifadeyle $\mathrm{p}<0,01$ düzeyinde anlamlı olduğu görülmektedir. Ancak risk alma boyutunun $\left(\mathrm{R}_{2}=, 003 ; \mathrm{F}=1,099 ; \mathrm{p}=, 295\right)$ anlamlı olmadığ $(\mathrm{p}>, 005)$ görülmektedir. Atık değerler arasında otokorelasyon olup olmadığını gösteren Durbin-Watson istatistiği değerlerinin 1,5 - 2 arasında olup, otokorelasyon olmadığı söylenebilir. Tüm bu bulgular ışığında araştırmada, algılanan örgütsel destek çalışanların iç girişimcilik boyutlarından yenilik, proaktiflik, özerklik performanslarını anlaml ve pozitif yönde etkilediği yani $\mathrm{H}_{1 \mathrm{a}}, \mathrm{H}_{1 \mathrm{c}}, \mathrm{H}_{1 \mathrm{~d}}$ hipotezlerinin desteklendiği, risk alma boyutunun ise iç girişimciliği etkilemediği yani $\mathrm{H}_{1 \mathrm{~b}}$ hipotezinin desteklenmediği söylenebilir.

\section{SONUÇ VE ÖNERILLER}

Apple'ın eski yöneticisi Steve Jobs "Müşterinize ne istediğini sorup ona göre ürün çıkaramazsınız, çünkü siz onların istediğini yaparken onlar başka bir şey istiyor olacaktır" sözü ile insan ihtiyaçlarının ne denli hızlı değiştiğini ve bu değişimi yakalayabilmek için örgüt çalışanlarının yaratıcı düşünce yapısına sahip, yenilikçi, risk alabilen, proaktif ve özgün bireylerden oluşmasının ne denli önemli olduğunu belirtmektedir. Sosyal mübadele kuramının mantığında kazan-kazan anlayışı vardır. Örgütler rekabetçi ortamda rakipleriyle yarışabilmesi, yenilikçi olabilmesi ve hayatta kalabilmesi için çalışanlarına ihtiyaç duyarken, çalışanlarda kendi hedeflerini gerçekleştirmek için kariyer sahibi olacağı bir örgüte ihtiyaç duyabilirler. Aslında amaçlarla yönetim 1şığında, örgüt içerisinde ye alan tüm paydaşların amaçlarını ve hedeflerini gerçekleştirebileceği bir zeminin yaratılması örgütsel etkinlik ve verimlilik için bir gerekliliktir (Yıldız ve Çobanoğlu, 2006a: 135-139; Yıldız ve Çobanoğlu, 2006b: 343). Bu gerekliliğe ulaşmada örgütün çalışanlarına verdiği desteği, çalışanların olumlu algılayıp performanslarını yükseltmesi, hem örgütün hem de çalışanın amaçlarına ulaşmada önemli olabilir.

Araştırmanın temel hipotezi olan "algılanan örgütsel destek çalışanların 
iç girişimcilik performanslarını pozitif yönde etkiler” desteklenmiştir. Algılanan örgütsel destek sayesinde çalışanlar örgüt yararına yönelik davranışlar sergiler, işlerine karşı daha motive olurlar ve örgüte olan bağl1lıkları artar. Örgütün desteğini hisseden çalışanların iç girişimcilik performansları artabilir ve işlerinde daha etkin ve verimli çalş̧abilirler. $\mathrm{Bu}$ durum hem örgüt için amaçlarına ulaşmada bir kazanç sağlayabilir, hem de çalışan hedeflerine ulaşabilir. Turgut (2014) tarafından gerçekleştirilen araştırmada, algılanan örgütsel desteğin iç girişimcilik üzerinde olumlu yönde (performans arttırıcı) etkisinin olduğu vurgulanmaktadır. Duygulu vd, (2008) ve Uçar ve Ötken (2010) tarafından gerçekleştirilen araştırmalarda, algılanan örgütsel desteğin örgütsel bağlılık üzerinde olumlu bir etkisi olduğu saptanmıştır. Aynı şekilde Turunç ve Çelik (2010) araştırmalarında algılanan örgütsel destek ile örgütsel özdeşleşme arasında olumlu, iş/aile, aile/iş ve işten ayrılma niyeti üzerinde olumsuz etkiye sahip olduğunu göstermişlerdir. Alt hipotezlere ait bulgular incelendiğinde, algılanan örgütsel destek çalıșanların iç girișimcilik boyutlarına (yenilik, proaktiflik, özerklik) ilişkin performanslarını anlamlı ve pozitif yönde etkilediği, ancak risk alma boyutu ile herhangi bir nedensellik ilişkisinin olmadığı ortaya çıkmıştır. Örgütsel destek algısı yüksek olan çalışanların örgütsel bağlılığı daha yüksek olabilir, daha fazla sorumluluk alabilir ve yüksek örgütsel vatandaşlık davranışı gösterebilir. Örgütsel destek sayesinde sosyoduygusal ihtiyaçları tatmin olan çalışanlar daha yüksek sorumluluk duygusuna sahip olabilir, yeni fikir ve ürünler geliştirebilir, daha fazla öngörümcü (proaktif) ve özgün olabilir. Örgütün desteğini yanında hisseden çalışanların daha yüksek iş çıktıları ve performans sundukları söylenebilir.

Araştırmanın sınırlılıkları, araştırmanın ankastre üretiminde faaliyetlerini sürdüren ve 80 ülkeye ihracat yapan Silverline A.Ş.'deki çalışanlarla yürütülmesi ve veri toplamak için seçilen ve kullanılan ölçekler olarak belirtilebilir. $\mathrm{Bu}$ sınırlılıklar ve araştırma sonuçları kapsamında, örgütlere, yöneticilere, araştırmacılara, paydaşlara, çalışanlara yol göstermek, katkıda bulunmak ve bundan sonra yapılacak araştırmalara ışı tutmak amacıyla bazı önerilerde bulunulmaktadır. Örgütler, tüm yönetici ve çalışanlarının karar verme, risk alabilme, öngörümcü olabilme, yaratıcı özelliklerini ortaya çıkarabilme ve bunu yenilik yaparak mal ve hizmete dönüştürebilme becerilerine sahip olabilmeleri için hizmet içi eğitim programları, kurs, seminer, çalıştay, konferans vb. düzenleyebilirler. Yöneticiler, çalışanlarının performans değerlemelerini yaparken, yenilikçi, girişimci, risk alma ve proaktiflik, özgünlük gibi kriterleri göz önünde bulundurabilirler ve çalışanlarını bu özelliklerini geliştirmeleri konusunda teşvik edebilirler. Örgütler, çalışanlarına her konuda destek sağlayabilirler ve bunu çalışanlarının algılayabilmesi için gerekli ortamı hazırlayabilirler. Örgütler, projeye dönüşen, oradan yeni ürün haline gelen fikirleri ödüllendirebilir ve diğer çalışanlar arasında yayılması için 
teşvik edebilirler. Örgütler, çalışanlarını örgütün hedefleri ve kendilerinden beklentileri konusunda bilgilendirebilirler ve yönlendirebilir. Araştırmacılar, iç girişimcilik ve algılanan örgütsel destek ile ilgili farklı sektörlerde, farklı örneklem gruplarıyla ve farklı değişkenlerle araştırmalar yapabilir.

\section{KAYNAKÇA}

AKIN, M. (2008), Örgütsel Destek, Sosyal Destek ve İş/Aile Çatışmalarının Yaşam Tatmini Üzerindeki Etkileri, Sosyal Bilimler Enstitüsü Dergisi, 2008/2(25): 141-170.

AKKOÇ, İ., ÇALIŞKAN, A. ve TURUNÇ, Ö. (2012), Örgütlerde Gelişim Kültürü ve Algılanan Örgütsel Desteğin İş Tatmini ve İş Performansına Etkisi: Güvenin Aracılık Rolü, Yönetim ve Ekonomi, 19(1): 105-135.

ALLEN, L. S., SMITH, E. J. ve SILVA D. N. (2013), Organizational Change and Organizational Creativity Perceptions from Nonprofit Organizational Members, Nonprofit Management and Leadership, 24(1): 23-42.

BASHIR, S. (2012), Perceived Organizational Support and The Cross-Cultural Adjustment of Expatriates in the UAE, Education, Business and Society: Contemporary Middle Eastern Issues, 5(1): 63-82.

BASIM, H. N., MEYDAN, C. H. ve ŞEŞEN, H. (2009), Bireyin Örgütsel Adalet Algısının İ Ģ Girişimcilik Davranışı ile İlişkisi: Kamuda Bir Araştırma, İşletme ve Finans Dergisi, 24(274): 1-19.

BOGLER, R. ve NIR, E. A. (2012), The Importance of Teachers' Perceived Organizational Support to Job Satisfaction: What's Empowerment Got to Do With It?, Journal of Educational Administration, 50(3): 287-306.

BORZA, A. ve MAIER, V. (2012), The Growing Importance of Intrapreneurship and its Impact upon The Survival of Companies, Revista de Management ci Inginerie Económica, 11(4): 13-22.

BOUCHARD, V. ve BASSO, O. (2011), Exploring the Links between Entrepreneurial Orientation and Intrapreneurship in SMEs, Journal of Small Business and Enterp. Dev., 18(2): 219-231.

BOYER, L. S., ARTIS, B. A., FLEMING, E. D. ve SOLOMON, J. P. (2014), The Impact of Perceived Organizational Support on Self-Directed Learning in Sales Training, Journal of Marketing Channels, 21: 65-76.

BYRNE, S. Z. ve HOCHWARTER, A. W. (2008), Perceived Organizational Support and Performance:Relationships Across Levels of Organizational Cynicism, Journal of Managerial Psychology, 23(1): 54-72.

CAO, L., HIRSCHI, A. ve DELER, J. (2014), Perceived Organizational Support and Intention to Stay in Host Countries Among Self-Initiated Expatriates: The Role of Career Satisfaction and Networks, The International Journal of Human Resource Management, 25(14): 2013-2032.

CHANG, J. (2001), Intrapreneurship and Exopreneurship in Manufacturing Firms: An Empirical Study of Performance Implications, Journal of Enterprising Culture, 9(2): 153-171.

CHERISTENSEN, S. K. (2005), Enabling Intrapreneurship: The Case of a Knowledge Intensive Industrial Company, European Journal of Innovation Management, 
8(3): 305-322.

DECONINCK, B. J. ve JOHNSON, T. J. (2009), The Effects of Perceived Supervisor Support, Perceived Organizational Support, and Organizational Justice on Turnover among Salespeople, Journal of Personal Selling and Sales Management, XXIX(4): 333-350.

DEMIREL, Y. ve ÖZBEZEK, D. B. (2015), işletmelerde iç Girişimcilik ve Yenilik ilişkisine Yönelik Kavramsal Bir İnceleme, TISK Akademi, 10(17): 113- 135.

DUYGULU, E., ÇIRAKLAR, N. ve MOHAN, Y. (2008), Algılanan Örgütsel Destek, İşe Bağll1ık ve İş Doyumunun Örgütsel Bağll1k Üzerine Etkisi, Celal Bayar Üniversitesi Sosyal Bilimler Dergisi, 6(1): 108-128.

EBNER, L. M., KORUNKA, C., FRANK, H. ve LUEGER, M. (2007), Intrapreneurship in Early Vocational Training: Definition and Operationalization. Zeitschrift für Personalf. 22(3): 291-311.

EDER, P. ve EISENBERGER, R. (2008), Perceived Organizational Support: Reducing the Negative Influence of Coworker Withdrawal Behavior, Journal of Management, 34(1): 55-68.

EISENBERGER, R., HUNTINGTON, R., HUTCHISON, S. ve SOWA, D. (1986), Perceived Organizational Support, Journal of Applied Psychology, 71(3): 500507.

EISENBERGER, R., JONES, R. J., ASELAGE, J. ve SUCHARSKI (2004), Perceived Organizational Support", The Employment Relationship: Exmining Psychological and Contextual Perfectives, Oxford University Pres.

FELICIO, J. A., RODRIGUES, R. ve CALDEIRINHA, R. V. (2012), The Effect of Intrapreneurship on Corporate Performance, Management Decision, 50(10): 1717-1738.

FIŞ, M. A. ve WASTİ, S. A. (2009), Örgüt Kültürü ve Girişimcilik Yönelimi İlişkisi, ODTÜ Gelişim Dergisi, 35: 127-164.

GAVINO, C. M., WAYNE, J. S. ve ERDOGAN, B. (2012), Discretionary and Transactional Human Resource Practices and Employee Outcomes: The Role of Perceived Organizational Support, Human Resource Management, 51(5): 665-686.

GÜREL, B. B. E. (2012), İç Girişimcilik: Literatür Taraması, Gümüşhane Üniversitesi Sosyal Bilimler Elektronik Dergisi, 6: 56-75.

HASHEMI, K. M. S., NADI, K. H., HOSSEINI, M. S. ve REZVANFAR, A. (2012), Agricultural Personnel's Proactive Behavior: Effects of Self Efficacy Perceptions and Perceived Organizational Support, International Business and Management, 4(1): 83-91.

HELlMAN, M. C., FUQUA, R. D. ve WORLEY, J. (2006), A Reliability Generalization Study on the Survey of Perceived Organizational Support: The Effects of Mean Age and Number of Items on Score Reliability, Educational and Psychological Measurement, 66(4): 631-642.

HU, C., WANG, S., YANG, C. ve WU, T. (2014), When Mentors Feel Supported: Relationships with Mentoring Functions And Proteges' Perceived Organizational Support, Journal of Organizational Behavior, 35: 22-37.

İÇERLİ, L., YILDIRIM, H. M. ve DEMİREL, Y. (2011), Kobilerde İç Girişimciliğin 
İncelenmesine Yönelik Bir Araştırma: Aksaray Örneği, Organizasyon ve Yönetim Bilimleri Dergisi, 3(2): 177-187.

KANBUR, A. ve KANBUR, E. (2014), Yenilik Kaynaklarının Kullanılma Düzeyinde Beyaz Yakalılar Arasındaki Farklılıkların İncelenmesi, Uluslararası Yönetim ve Sosyal Araştırmalar Dergisi, 1(1): 10-23.

KANBUR, A. (2015), Innovative Behaviors in the Wake of Vitality, Entrepreneurship and Innovation Management Journal, 3(1): 40-50.

KASALAK, G. ve AKSU, B. M. (2014), Araştırma Görevlilerinin Algıladıkları Örgütsel Desteğin Örgütsel Sinizm ile İlişkisi, Kuram ve Uygulamada Eğitim Bilimleri, 14(1): 115-133.

KOÇ, K. ve MENTE, A. (2007), İnovasyon Kavramı ve Üniversite-Sanayi-Devlet İşbirliğinde Üçlü Sarmal Modeli, Hacettepe Üniversitesi Sosyolojik Araştırmalar e-dergisi, 1-18.

MOLINA, C. ve CALLAHAN, L. J. (2009), Fostering Organizational Performance; The Role of Learning and Intrapreneurship, Journal of European Industrial Training, 33(5): 388-400.

MOON, W. T., HUR, W. ve JUN, J. (2013), The Role of Perceived Organizational Support on Emotional Labor in The Airline Industry, International Journal of Contemporary Hospitality Management, 25(1): 105-123.

MORIANO, A. J., MOLERO, F., TOPA, G. ve MANGIN, L. J. (2014), The Influence of Transformational Leadership and Organizational Identification on Intrapreneurship, Int Entrep Manag J., 10: 03-119.

MOURA, E. P. ve ABRUNHOSA, A. (2007), The Role of TQM Practices in Technological Innovation: The Portuguese Footwear Industry Case, Total Quality Management \& Business Excellence, 18(1): 57-66.

NEVES, P. ve EISENBERGER, R. (2012), Management Communication and Employee Performance: The Contribution of Perceived Organizational Support, Human Performance, 25: 452-464.

POTTS, N. L. ve REYNOLDS, D. (2010), The Effect of Supervisor-Subordinate Language Similarity on Subordinates' Perceived Organizational Support in the U.S. Lodging Industry, Journal of Human Resources in Hospitality and Tourism, 9: 92-102.

RAMANIGOPAL, S.C., PALANIAPPAN, G., HEMALATHA, N. ve MURUGESAN, G. (2012), Corporate Entrepreneurship - a Business Strategy, International Journal of Research in Commerce, Economics \& Management, 2(11): 51-54.

RIGTERING, J. P. C. ve WEITZEL, U. (2013), Work Context and Employee Behaviour as Antecedents for Intrapreneurship, Int. Entrep. Manag. J., 9: 337360.

SCOTT, P., GIBBONS, P. ve COUGHLAN, J. (2010), Developing Subsidiary Contribution to The MNC-Subsidiary Entrepreneurship and Strategy Creativity, Journal of International Management, 16: 328-339.

SOLEIMANI, M., HAMIDIBEINABAJ, M. ve BAFRANI, J. M. (2013), Studying the Relationship among Components of Knowledge Management and Corporate Entrepreneurship, Advances in Environmental Biology, 7(8): 1643-1647.

STULL, M. ve ARAM, D. J. (2010), Exploring Trust as an Influencing Mechanism of 
Intrapreneurship, International Journal of Management and Marketing Research, 3(3): 17-38.

SUAZO, M. M. ve TURNLEY, H. W. (2010), Perceived Organizational Support as a Mediator of The Relations Between Individual Differences and Psychological Contract Breach, Journal of Managerial Psychology, 25(6): 620-648.

TOKGÖZ, N. (2011), Örgütsel Sinisizm, Örgütsel Destek ve Örgütsel Adalet İlişkisi: Elektrik Dağıtım İşletmesi Çalışanları Örneği, Eskişehir Osmangazi Üniversitesi IIIBF Dergisi, 6,(2): 363-387.

TURGUT, H. (2014), Algılanan Örgütsel Desteğin İşletme Performansına Etkisinde İç Girişimciliğin Aracılık Rolü, Işsletme Araştırmaları Dergisi, 6(3): 29-62.

TURUNÇ, Ö. ve ÇELİK, M. (2010), Algılanan Örgütsel Desteğin Çalışanların İş- Aile, Aile-İş Çatışması, Örgütsel Özdeşleşme ve İşten Ayrılma Niyetine Etkisi: Savunma Sektöründe Bir Araştırma, A.Ü. SBE Dergisi, 14(1): 209-232.

TURUNÇ, Ö. ve ÇELİK, M. (2010), Çalışanların Algıladıkları Örgütsel Destek ve İş Stresinin Örgütsel Özdeşleşme ve İş Performansına Etkisi, Yönetim ve Ekonomi, 17(2): 183-206.

TÜZÜN, K. İpek ve KALEMCİ, R. Arzu (2016), İKY İşlevleri ve Hat Yöneticileri Etkililiğinin Çalışan İş Performansına Etkileri Üzerine Bir Araştırma, 24. Yönetim ve Organizasyon Kongresi, İstanbul.

UÇAR, D. ve ÖTKEN, B. A. (2010), Algılanan Örgütsel Destek ve Şirkete Bağl1lık: Örgüt Temelli Öz-Saygının Rolü, Dokuz Eylül Üniversitesi İktisadi ve İdari Bilimler Fakültesi Dergisi, 25(2): 85-105.

WARRIAN, P. ve MULHERN, C. (2005), Knowledge and Innovation in the Interface Between the Steel and Automotive Industries: The Case of Dofasco, Regional Studies, 39(2): 161-170.

WYK, R. V. ve ADONISI, M. (2012), Antecedents of Corporate Entrepreneurship, S.Afr.J.Bus.Manage., 43(3): 65-78.

YILDIZ, B. ve YILDIZ, H. (2015), The Effect of Servant Leadership and Psychological Ownership: The Moderator Role of Organizational Support, Journal of Global Strategic Management, 9(2): 65-77.

YILDIZ, B., ERAT, S., ALPKAN, L., YILDIZ, H. ve SEZEN, B. (2015), Drivers of Innovative Constructive Deviance: A Moderated Mediation Analysis, World Conference on Technology, Innovation and Entrepreneurship (WCTIE), 28-30May 2015, Istanbul University, Istanbul-TURKEY. (Procedia - Social and Behavioral Sciences-195, 1407-1416. doi:10.1016/j.sbspro.2015.06.436.

YILDIZ, H. ve YILDIZ, B. (2016), The Effects of Ethical Leadership, Servant Leadership and Leader-Member Exchange on Compulsory Citizenship Behaviors, International Business Research, 9(2): 19-33.

YILDIZ, H. ve ÇOBANOĞLU, N. Ö. (2016a). Amaçlara Göre Yönetim: Türk Kamu Yönetimine Yansımaları, Research Journal of Business and Management, 3(2): 134-146.

YILDIZ, H. ve ÇOBANOĞLU, S. (2016b). Tracking Clues of the Management by Objectives in Today's Turkish Public Administration Area, Global Business Research Congress (GBRC), 26-27-May 2016, İstanbul/TURKEY. (PreesAcademia Procedia, 342-348. doi: 10.17261/Pressacademia.2016118654. 
ZACHER, H. ve WINTER, G. (2011), Eldercare Demands, Strain, and Work Engagement: The Moderating Role of Perceived Organizational Support, Journal of Vocational Behavior, 79: 667-680.

ZAHRA, A. S. ve GARVIS, M. D. (2000), International Corporate Entrepreneurship and Firm Performance: The Moderating Effect of International Environmental Hostility, Journal of Business Venturing, 15: 469-492. 